\title{
Isolated facet joint fracture as a cause of chronic low back pain and sciatica
}

\author{
Robert W Teasell MD FRCPC
}

RW Teasell.

Isolated facet joint fracture as a cause of chronic low back pain and sciatica.

Pain Res Manage 1996;1(3):175-177.

A case of facet joint fracture following a rear-end motor vehicle accident who presented with chronic low back pain and sciatica is outlined. Diagnosis was made with ${ }^{99} \mathrm{Tc}$ nuclear bone scan and was confirmed on computed tomographic scan after diagnosis with regular radiographs had failed. Facetectomy relieved pain but led to symptoms related to asymmetric load on the opposite facet joint. Symptoms were substantially relieved with a facet joint deinnervation procedure. Facet joint fracture was felt to occur as a consequence of compression forces on the facet joint at the time of impact.

Key Words: Facet joint fracture, Facetectomy, Motor vehicle accident, Sciatica

\section{Fracture isolée d'une facette articulaire comme cause de lombalgie chronique et de sciatalgie}

RÉSUMÉ : On décrit le cas d'un homme souffrant d'une fracture d'une facette articulaire à la suite d'un accident où la voiture qu'il conduisait fut percutée à l'arrière. Cette fracture se manifestait sous la forme d'une lombalgie chronique et d'une sciatalgie. Le diagnostic a été posé au moyen d'une scintigraphie osseuse au $\mathrm{Tc}^{99}$, et confirmé par tomodensitométrie, alors que les radiographies ordinaires n'avaient rien révélé d'anormal. L'excision de la facette a entrainé un soulagement de la douleur mais a entraîné l'apparition de symptomes liés à une charge asymétrique sur la facette ariiculaire opposée. Ces symptômes ont été considérablement soulagés en procédant à une dénervation de la facette articulaire. On pense que la fracture de la facette articulaire résulte des forces compressives sur la facette articulaire au moment de l'impact.
$\mathrm{F}$

acet joint fractures have been reported as part of more extenI sive injuries to the lumbar or cervical spine. However, isolated facet joint fractures appear to be uncommon. A case of isolated facet joint fracture presenting as chronic low back pain and sciatica is presented. Some problems in the management of facet joint fractures are also discussed.

\section{CASE PRESENTATION}

A 30-year-old male presented to a chronic pain clinic with a five-year history of right lower lumbar and buttock pain. The pain began five years previously when the vehicle he was driving was rear-ended at a high rate of speed. At impact he extended backwards with sufficient force to dislodge the car seat from its moorings and was then thrown forward when his vehicle struck another vehicle in front. He initially presented with neck pain, left arm paraesthesia and right lumbar/buttock pain. The neck and arm symptoms resolved, although the right lumbar/buttock pain worsened and he developed right leg paraesthesia.

He was reviewed by two orthopedic surgeons who performed $\mathrm{x}$-rays of the lumbosacral spine. These were reportedly normal and the patient was given a diagnosis of soft tissue injuries. He was treated with physiotherapy, a corset, nonsteroidal antiinflammatory drugs and narcotics. He remained partially disabled by the pain.

When the patient was reviewed five years following the accident, pain was focused over the right sacroiliac joint and buttock. He had associated leg pain and numbness extending to the lateral foot. Pain was made worse with sitting, standing and

Physical Medicine and Rehabilitation, University Hospital, University of Western Ontario, London, Ontario

Correspondence and reprints: Dr Robert Teasell, University Hospital, 339 Windermere Road, London, Ontario N6A 5A5. Telephone 519-663-3235, fax 519-663-2941

Received for publication October 18, 1995. Accepted January 5, 1996 

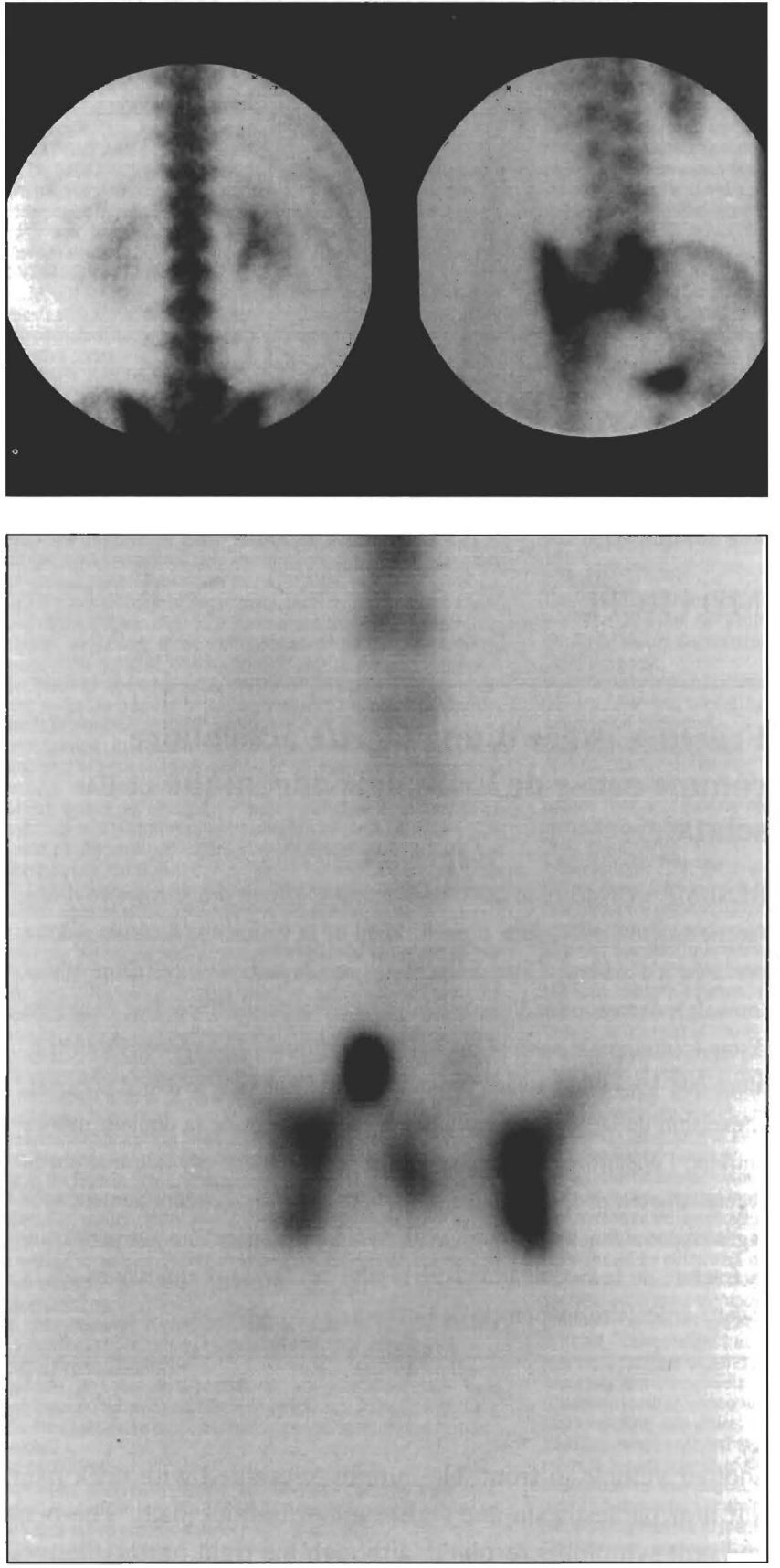

Figure 1) Top Three phase nuclear bone scan of the lumbosacral spine demonstrating well circumscribed intense abnormal uptake of activity at the right L5 to S1 facet joint. Bottom A tomographic scan shows this clearly

extending backwards. On examination he was able to flex forward to touch his knees while extension was severely limited. Straight leg raise was positive on the right, he had an antalgic gait and tenderness over the right L5 paraspinal musculature.

A bone scan showed markedly increased uptake over the right L5 to S1 fact joint (Figure 1). Computed tomographic scan showed a fractured L5 to S1 facet joint with bony hypertrophy, an apparent pseudoarthrosis and compression of the lateral recess (Figure 2). The patient was referred to a neurosurgeon who performed a partial right L5 to S1 facetectomy with hemi-


Figure 2) Computed tomographic scans at the level of L5 to S1 demonstrating a fractured $\mathrm{L} 5$ to $\mathrm{S} 1$ facet joint with bony hypertrophy, an apparent pseudoarthrosis and some compression of the adjacent lateral recess

laminectomy and right L5 and S1 foraminotomies. Initially the patient's pain improved with a significant reduction in his right leg paraesthesia. However, his right leg pain returned and an S1 nerve root block at that time completely eliminated his right leg pain.

Approximately six months after the initial operation he underwent a complete facetectomy and foraminotomy. Right-sided back and leg pain improved but he developed left lower back and buttock pain, and eventually left leg paraesthesia. Magnetic resonance image scanning showed only the complete right L5 to S1 facetectomy. There was no gross instability noted on flexionextension lumbosacral spine $x$-rays. Bone scan showed some increased uptake involving the left L5 to S1 facet joint. A left L5 to $\mathrm{S} 1$ facet joint block provided 15 to 20 mins of pain relief. It was felt that a significant portion of his pain was due to mechanical asymmetric loading of the left L5 to S1 facet joint following the right L5 to S1 facetectomy. An L5 to S1 fusion was recommended but after discussion with the patient he decided to defer any further surgical procedures. However, he continued to experience low back pain and eventually agreed to an L5 to S1 fora-minotomy and left L5 to S1 facet joint denervation. He experienced a significant reduction in his pain after this operation. 


\section{DISCUSSION}

This case illustrates an unusual cause of chronic low back pain and sciatica that, surprisingly, did not appear on standard $x$-rays. Facet joint fracture is a rare cause of low back pain, although injury to the facet joint has been implicated as a possible source of the low hack pain frequently seen following the flexionextension trauma associated with motor vehicle accidents (1). Several authors (2-9) have shown the presence of fractures to the cervical facet joints and adjacent articular pillars after whiplash injuries.

Twomey et al (1) studied three zygapophyseal joints from each of 31 lumbar spines of subjects who died of accidental injuries, mostly as a result of motor vehicle accidents. Bony injuries, in the form of superior articular process fractures or infractions of the subchondral bone plate and soft tissue injuries to the capsule or articular cartilage, were found in at least one joint in 24 of the 31 subjects ( $77 \%$ ). Only two subjects who died in a motor vehicle accident showed no evidence of facet joint injuries. In a comparable group of 25 young individuals who died nonviolent deaths, only six of the 119 joints sectioned showed similar injuries. None of the lesions was reportedly visible on normal lateral and anterior-posterior $\mathrm{x}$-rays of the lumbar spines (1).

Discernable facet joint fractures are rarely seen as an isolated phenomena because this type of injury generally occurs in association with more severe trauma. The facet joint fracture likely

\section{REFERENCES}

1. Twomey LT, Taylor JR, Taylor MM. Unsuspected damage to lumbar zygapophyseal (facet) joints after motor vehicle accidents. Med J Aust 1989;151:210-7.

2. Abel MS. Moderately severe whiplash injuries of the cervical spine and their roentgenologic diagnosis. Clin Orthop 1958;12:189-208.

3. Abel MS. Occult traumatic lesions of the cervical vertebrae. CRC Crit Rev Clin Radiol Nuclear Med 1975;6:469-553.

4. Abel MS. The radiology of chronic neck pain: sequelae of occuit traumatic lesions. CRC Crit Rev Diag Imag $1982 ; 20: 27-78$. occurred in response to the compression load on the posterior aspects of the spine during the violent extension movements of the spine.

Facetectomy was initially regarded as a simple solution to this patient's low back pain, ie, remove the area of intense inflammation as shown on bone scan and decompress the nearby nerve root in the process. However it failed to take into account the increased stress on the left L5 to S1 facet joint as a result of asymmetric mechanical loading following removal of the right L5 to S1 facet joint. In retrospect, a fusion of L5 to S1 may have prevented development of left L5 to S1 facet joint difficulties although it is uncertain whether an additional fusion operation would have provided a new nidus for pain. Fortunately, a left $L 5$ to $\mathrm{S} 1$ facet joint deinnervation procedure significantly relieved his pain.

\section{CONCLUSIONS}

This case serves to illustrate one of those few cases where technetium nuclear bone scan proved to be beneficial in the diagnostic work-up of low back pain. It also illustrates that significant compressive forces can develop in the lumbosacral spine at the facet joint during a rear-end collision, in this case breaking the seat with force severe enough to lead to the fracture. This case suggests, in dramatic fashion, that the lower back pain frequently associated with rear-end collision may, at least in part, be due to injury of associated facet joints.

5. Binet EF, Moro JJ, Marangola JK, Hodge CJ. Cervical spine tomography in trauma. Spine 1977;2:163-72.

6. Clark CR, Igram CM, el Khowry GY, Ehara S. Radiographic evaluation of cervical spine injuries. Spine 1988;13:742-7.

7. Jeffreys $E$. Soft tissue injuries of the cervical spine. In: The Cervical Spine Research Society. Disorders of the Cervical Spine. Stoneham: Butterworth, 1980:81-9.

8. Jonsson $\mathrm{H} \mathrm{Jr}$, Bring G, Rauschning W, Sahlstedt B. Hidden cervical spine injuries in traffic accident victims with skill fractures. I Spinal Disord 1991:4:251-63.

9. Smith GR, Beckly DE, Abel MS. Articular mass fracture: a neglected cause of post traumatic neck pain? Clin Radiol 1976;27:335-40. 


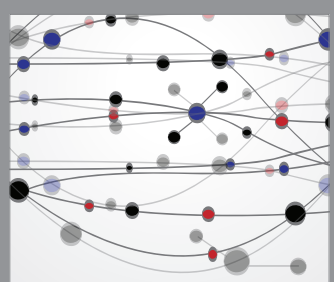

The Scientific World Journal
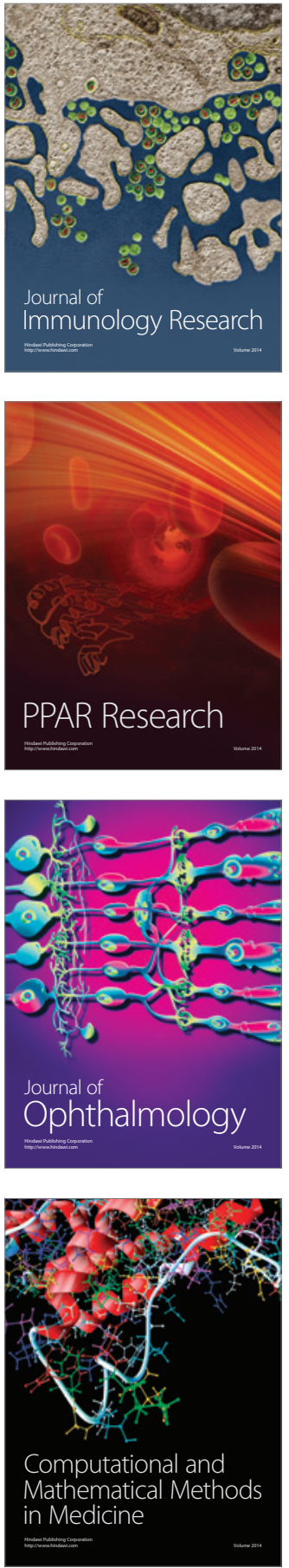

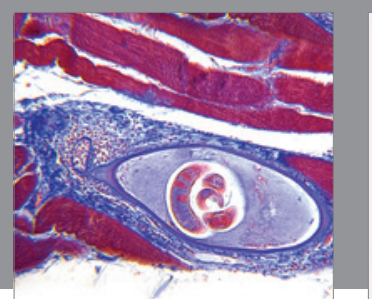

Gastroenterology Research and Practice

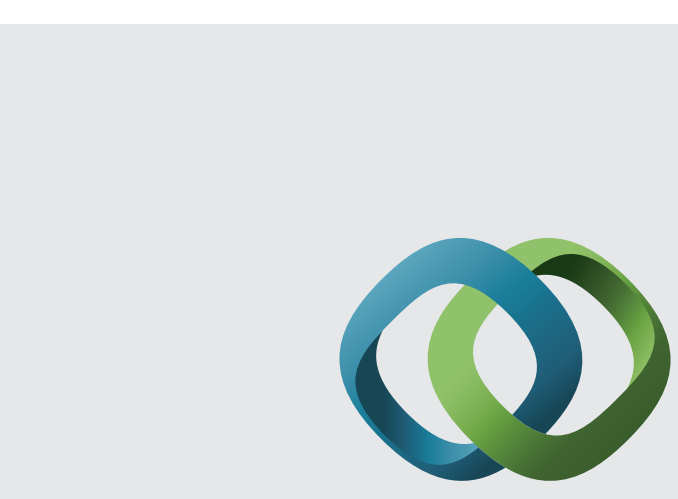

\section{Hindawi}

Submit your manuscripts at

http://www.hindawi.com
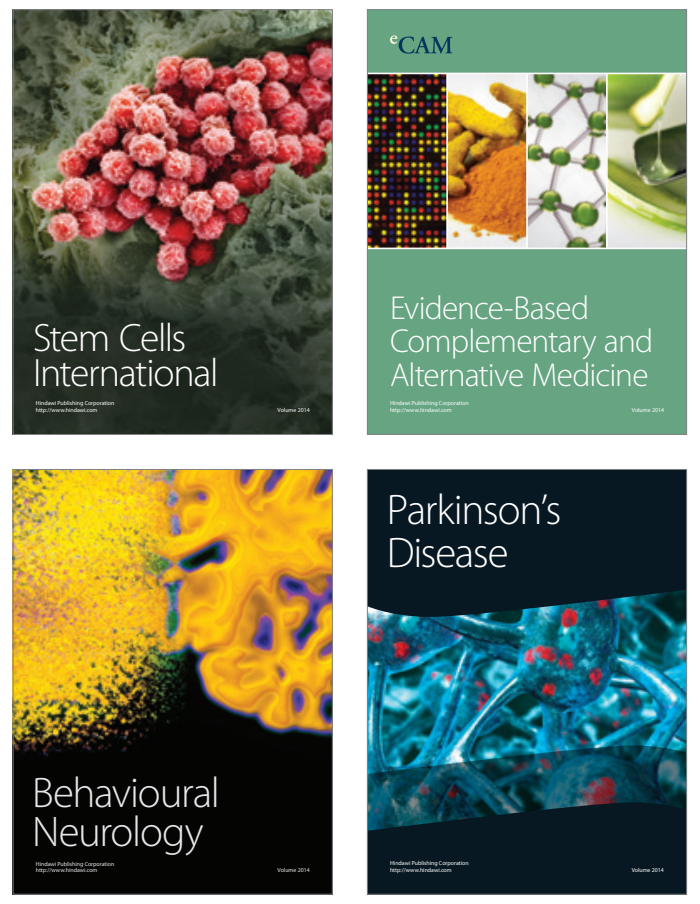
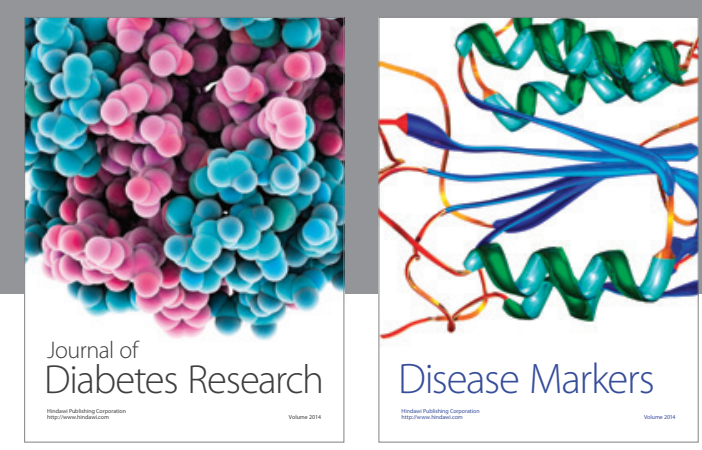

Disease Markers
